\title{
Properties of internal planetary-scale inertio gravity waves in the mesosphere
}

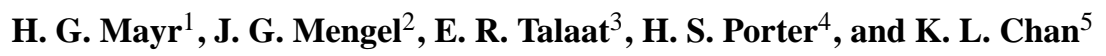 \\ ${ }^{1}$ Goddard Space Flight Center, Greenbelt, MD, 20771 , USA \\ ${ }^{2}$ Science Systems and Applications, Inc., Lanham, MD, USA \\ ${ }^{3}$ Applied Physics Laboratory, Johns Hopkins University, Laurel, MD, USA \\ ${ }^{4}$ Furman University, Greenville, SC, USA \\ ${ }^{5}$ Hong Kong University of Science and Technology, Hong Kong, China
}

Received: 25 March 2004 - Revised: 16 July 2004 - Accepted: 16 August 2004 - Published: 3 November 2004

\begin{abstract}
At high latitudes in the upper mesosphere, horizontal wind oscillations have been observed with periods around $10 \mathrm{~h}$. Waves with such a period are generated in our Numerical Spectral Model (NSM), and they are identified as planetary-scale inertio gravity waves (IGW). These IGWs have periods between 9 and $11 \mathrm{~h}$ and appear above $60 \mathrm{~km}$ in the zonal mean $(\mathrm{m}=0)$, as well as in $\mathrm{m}=1$ to 4 , propagating eastward and westward. Under the influence of the Coriolis force, the amplitudes of the waves propagating westward are larger at high latitudes than those propagating eastward. The waves grow in magnitude at least up to about $100 \mathrm{~km}$ and have vertical wavelengths around $25 \mathrm{~km}$. Applying a running window of 15 days for spectral analysis, the amplitudes in the wind field are typically between 10 and $20 \mathrm{~m} / \mathrm{s}$ and can reach $30 \mathrm{~m} / \mathrm{s}$ in the westward propagating component for $\mathrm{m}=1$ at the poles. In the temperature perturbations, the wave amplitudes above $100 \mathrm{~km}$ are typically $5 \mathrm{~K}$ and as large as $10 \mathrm{~K}$ for $\mathrm{m}=0$ at the poles. The IGWs are intermittent but reveal systematic seasonal variations, with the largest amplitudes occurring generally in late winter and spring. Numerical experiments show that such waves are also generated without excitation of the migrating tides. The amplitudes and periods then are similar, indicating that the tides are not essential to generate the waves. However, the seasonal variations without tides are significantly different, which leads to the conclusion that non linear interactions between the semidiurnal tide and planetary waves must contribute to the excitation of the IGWs. Directly or indirectly through the planetary waves, the IGWs are apparently excited by the instabilities that arise in the zonal mean circulation. When the solar heating is turned off for $m=0$, both the PWs and IGWs essentially disappear. That the IGWs and PWs have common roots in their excitation mechanism is also indicated by the striking similarity of their seasonal variations in the lower mesosphere. Compared to the PWs, however, the planetary-scale
\end{abstract}

Correspondence to: H. G. Mayr

(hans.mayr@gsfc.nasa.gov)
IGWs propagate zonally with much larger phase speeds. In contrast to the PWs, the IGWs thus are not affected much by interactions with the background zonal winds whose seasonal variations drastically change with altitude in the mesosphere. Since the IGWs can propagate through the mesosphere without much interaction, except for viscous dissipation, one should then expect that they reach the thermosphere above with significant and measurable amplitudes.

Key words. Meteorology and atmospheric dynamics (general circulation; middle atmosphere dynamics; waves and tides)

\section{Introduction}

Distinct oscillations with periods around $10 \mathrm{~h}$ have been observed with various measurement techniques in the upper mesosphere.

Some of the earliest observations were reported by Manson et al. (1982) and Manson and Meek (1990), who analyzed MF radar measurements of winds at Saskatoon $\left(52^{\circ} \mathrm{N}\right)$ to study the dynamical components of the upper mesosphere. In addition to the tides and planetary waves that characterize the region, their analysis revealed persistent oscillations with periods of 9-10 and $16 \mathrm{~h}$, which the authors attributed to non linear coupling between semidiurnal tide and the 2-day wave. The same kind of wave oscillations were also observed by Ruster (1994) based on wind measurements from a VHF radar at $69^{\circ} \mathrm{N}$, and Sivjee et al. (1994) saw the waves at Eureka $\left(80^{\circ} \mathrm{N}\right)$ in Michelson interferometer measurements of temperature.

Hernandez et al. (1992) observed a pronounced westward propagating wave with a period of $10.1 \mathrm{~h}$ near the South Pole. The data were derived from Doppler shifting and a broadening of $\mathrm{OH}$ emissions at altitudes near $90 \mathrm{~km}$, which yielded winds and temperatures, respectively. Horizontal winds were additionally provided by the medium frequency radar mea- 
surements from the Scott Base at $78^{\circ} \mathrm{S}$ (Fraser, 1984). During the period of observations in August 1991 (austral winter), the 10-h wave was apparent in the wind data at both stations. The wave dominated at the South Pole, but at $78^{\circ} \mathrm{S}$ the semidiurnal tide was more prominent. Horizontal winds at the pole must have zonal wave number $\mathrm{m}=1$, and the observed phase progression revealed that the 10 -h wave was propagating westward. The related temperature variations for this wave number should vanish at the pole, and the analysis indeed showed that. Based on the measurements at both stations, Hernandez et al. (1992) concluded from the inferred vertical wavelengths of about $100 \mathrm{~km}$ that they probably observed an $\mathrm{m}=1 \mathrm{Lamb}$ wave with meridional wave number two. A 10 -h wave in the horizontal winds with $m=1$ was also observed by Hernandez et al. (1993) during the 1992 southern winter in the Antarctic polar region, but in this case it was accompanied by a westward propagating 12-h wave they called an inertio gravity wave. Forbes et al. (1995) also observed a 12-h wave in radar measurements near the North Pole and interpreted it to be a non-migrating semidiurnal tide.

Westward propagating wind oscillations with periods between about 7 and $12 \mathrm{~h}$ for $\mathrm{m}=1$ have been observed with meteor radar measurements near the South Pole $\left(88^{\circ} \mathrm{S}\right)$ during the winter months (Forbes et al., 1999; Portnyagin et al., 2000). The observations were interpreted in terms of "normal modes" or Lamb waves, but inertio gravity waves, nonlinear coupling between tides and planetary waves, and in-situ excitation of short-period waves were also mentioned as possible explanations.

Based on the measurements from an array of instruments at northern high latitudes, Wu et al. (2002) presented comprehensive observations of a 10-h oscillation in the temperature and wind fields of the mesosphere and lower thermosphere. By comparing the phase of the wave at different stations, a zonal wave number $\mathrm{m}=5$ was inferred, and the vertical wavelength was estimated to be about $53 \mathrm{~km}$. These wave properties led to the conclusion that nonlinear coupling between the semidiurnal tide and the 2-day planetary wave was the likely excitation mechanism.

In a recent paper (Mayr et al., 2003), we reported that our model produces in the upper mesosphere horizontal wind oscillations with periods around $10 \mathrm{~h}$. The oscillations were identified as internal planetary-scale inertio gravity waves (IGW), thought to be generated in the model by instabilities like the planetary waves. It is the purpose of the present paper to: a) describe more fully the IGWs in the temperature and wind fields that are generated by the model and b) amend our earlier interpretation by recognizing that nonlinear coupling between tides and planetary waves is also a likely excitation mechanism.

\section{Numerical spectral model}

The Numerical spectral model (NSM), introduced by Chan et al. (1994a), has been discussed extensively in the literature with 2-D and 3-D applications to describe the middle atmosphere dynamics (e.g. Mengel et al., 1995; Mayr et al., 2001, 2003, 2004). Since the present version of the NSM is virtually identical to the one employed in a recent study (Mayr et al., 2004), we summarize the essential features.

Formulated with spherical harmonics, the NSM is truncated at zonal wave number $\mathrm{m}=4$ and describes the tides and planetary waves, as well as the Semiannual Oscillation (SAO) and Quasi-biennial Oscillation (QBO) for $\mathrm{m}=0$. The maximum meridional wave numbers retained in the model is $\mathrm{n}=12$ to yield 12 Gaussian points per hemisphere. In the vertical, the integration step is $0.5 \mathrm{~km}$ (below $120 \mathrm{~km}$ ), and the time step is typically about $5 \mathrm{~min}$.

In the zonal mean $(\mathrm{m}=0)$, the NSM is driven by UV radiation absorbed in the mesosphere and stratosphere (Strobel, 1978) and by EUV radiation absorbed in the thermosphere. A heat source is also applied in the troposphere to reproduce qualitatively the observed zonal jets and temperature variations near the tropopause. Separate from $=0$, the solar heating rates for the thermally driven migrating tides with $m=1$ and 2 in the middle atmosphere and troposphere are taken from Forbes and Garrett (1978). The planetary waves (PW), and IGWs discussed here, are solely generated internally, i.e. without explicit excitation sources related to tropospheric convection or flow over topography. Newtonian cooling is applied to describe the radiative loss with a parameterization provided by Zhu (1989).

An important feature of the NSM is that it incorporates the Doppler Spread Parameterization (DSP) for small-scale gravity waves (GW) developed by Hines (1997a,b), which has also been applied successfully in a number of other models (e.g. Akmaev, 2001; Manzini et al., 1997).

\section{Model results}

\subsection{Wave patterns and global survey}

In light of the measurements by Hernandez et al. (1992) that were carried out at polar latitudes, we present with Fig. 1 the computed meridional winds a) at $84^{\circ} \mathrm{N}$ and b) $77^{\circ} \mathrm{N}$ for $\mathrm{m}=1$, covering the altitude range between 80 and $110 \mathrm{~km}$. (Horizontal winds at the poles must have zonal wave number $m=1$.) The winds are presented for a period of 4 days in March of the third model year, during a time when relatively large waves are generated with evident periodicities around $10 \mathrm{~h}$, as illustrated in two cases. With contour intervals of a) $10 \mathrm{~m} / \mathrm{s}$ and b) $6 \mathrm{~m} / \mathrm{s}$, the amplitudes are generally well above $20 \mathrm{~m} / \mathrm{s}$ and grow with height. Although the waves are highly variable, the pattern indicates downward phase propagation with vertical wavelengths of about $20 \mathrm{~km}$. Our analysis shows that the waves at polar latitudes propagate primarily westward and thus reproduce an important aspect of the observations by Hernandez et al. (1992), who inferred the same for their 10-h oscillation.

Temperature variations at the poles must have zonal wave number $m=0$. Analogous to Fig. 1, we present with Fig. 2 the computed temperature perturbations for this wave number at 


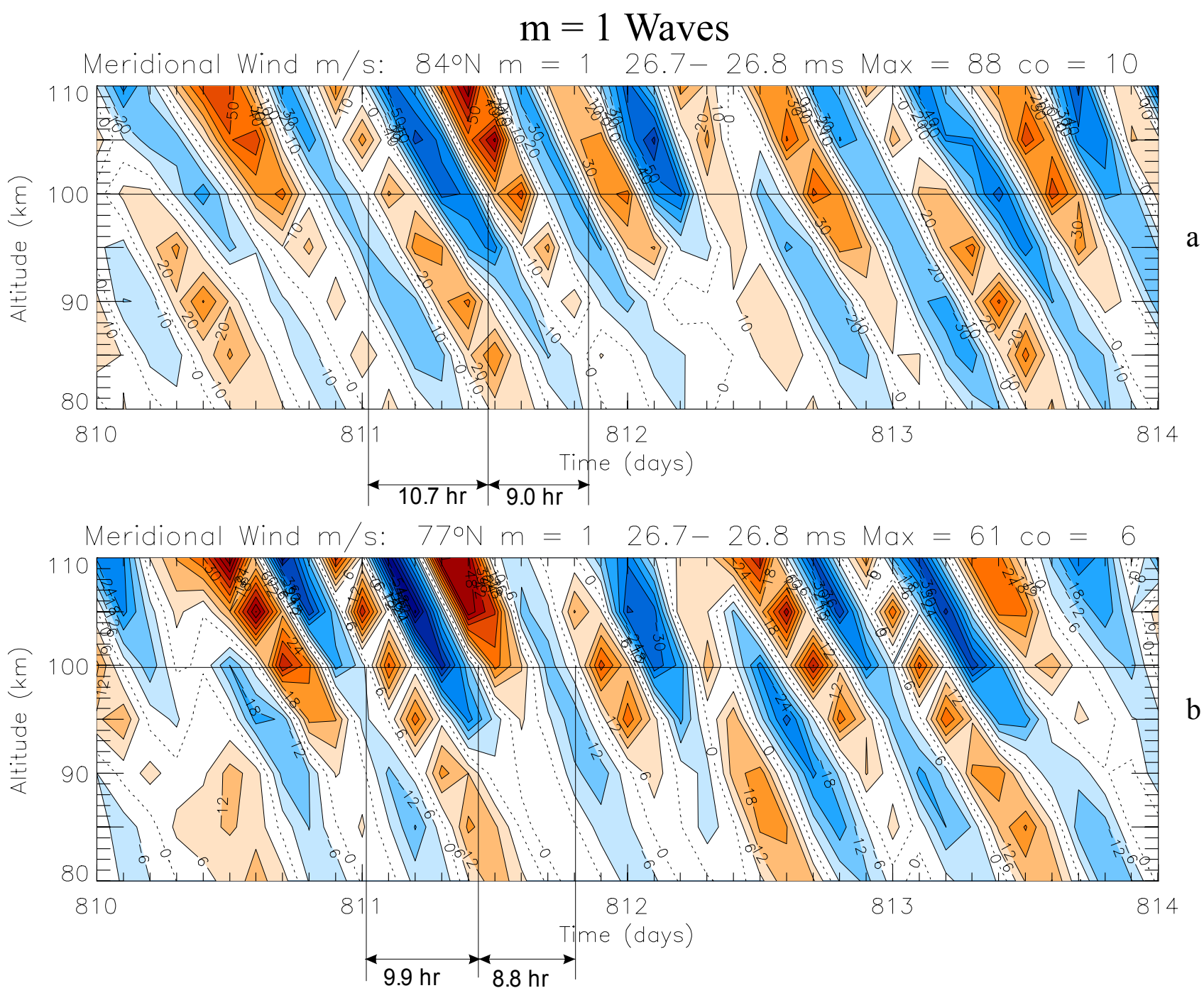

Fig. 1. Time-altitude contour plot of meridional winds for zonal wave number $\mathrm{m}=1$ at $84^{\circ} \mathrm{N}$ (a) and $77^{\circ} \mathrm{N}$ (b), Gaussian points, during March (late northern winter) of the third model year when waves with periods around $10 \mathrm{~h}$ are prominent at polar latitudes. The contour intervals are $10 \mathrm{~m} / \mathrm{s}$ (a) and $6 \mathrm{~m} / \mathrm{s}$ (b). For illustrative purpose, two examples of wave periods are identified from zero intersections. (To reduce output, the model results are recorded with 5-km altitude intervals, which causes the contours to appear ragged.)

a) $84^{\circ} \mathrm{N}$ and b) $70^{\circ} \mathrm{N}$, covering the same altitude range and time span. The displayed wave periods (from zero crossings) are between 9 and $10 \mathrm{~h}$, the vertical wavelengths are typically around $20 \mathrm{~km}$, and the amplitudes often exceed $5 \mathrm{~K}$ and tend to grow with altitude.

For $m=0$, the temperature waves are associated energetically with meridional (irrotational) wind oscillations, which we present in Fig. 2c for a latitude of $77^{\circ} \mathrm{N}$. With a contour interval of $4 \mathrm{~m} / \mathrm{s}$, the computed winds have amplitudes exceeding $20 \mathrm{~m} / \mathrm{s}$ and reveal periods similar to those apparent in the temperature. The vertical wavelengths are again close to $20 \mathrm{~km}$.

The above model results were displayed for selected zonal wave numbers to highlight the oscillations at high latitudes, $84^{\circ} \mathrm{N}$, close to the pole: for $\mathrm{m}=1$ and 0 in the meridional winds and temperature perturbations, respectively. The overall patterns would not be very different had we displayed in
Figs. 1 and 2 the results for the combined wave numbers $m=0$ to 4 retained in the model. Away from the pole, however, the variability and maximum amplitudes would be larger.

Anticipating results later discussed that reveal distinct seasonal variations, we present in Figs. 3 and 4 the meridional winds and temperature perturbations, respectively, for the time span 26 to 29 months (March through May). The maximum amplitudes are shown of the stationary wave for $\mathrm{m}=0 \mathrm{a}$ ), and the eastward $\mathrm{b}, \mathrm{c}$ ) and westward d,e) propagating waves for $\mathrm{m}=1$ and 2 with periods between 9 and $10.5 \mathrm{~h}$. For this time span and range of periods analyzed, the $m=1$ westward propagating wave in the meridional winds is largest, with $25 \mathrm{~m} / \mathrm{s}$ near $100 \mathrm{~km}$, and it peaks in the northern polar region. With a maximum amplitude of $19 \mathrm{~m} / \mathrm{s}$ near $75^{\circ} \mathrm{N}$, the stationary (non-migrating) wave for $\mathrm{m}=0$ is also prominent as Fig. 2c indicated. The asymmetry between the Northern and Southern Hemispheres, evident in all the wave numbers and 


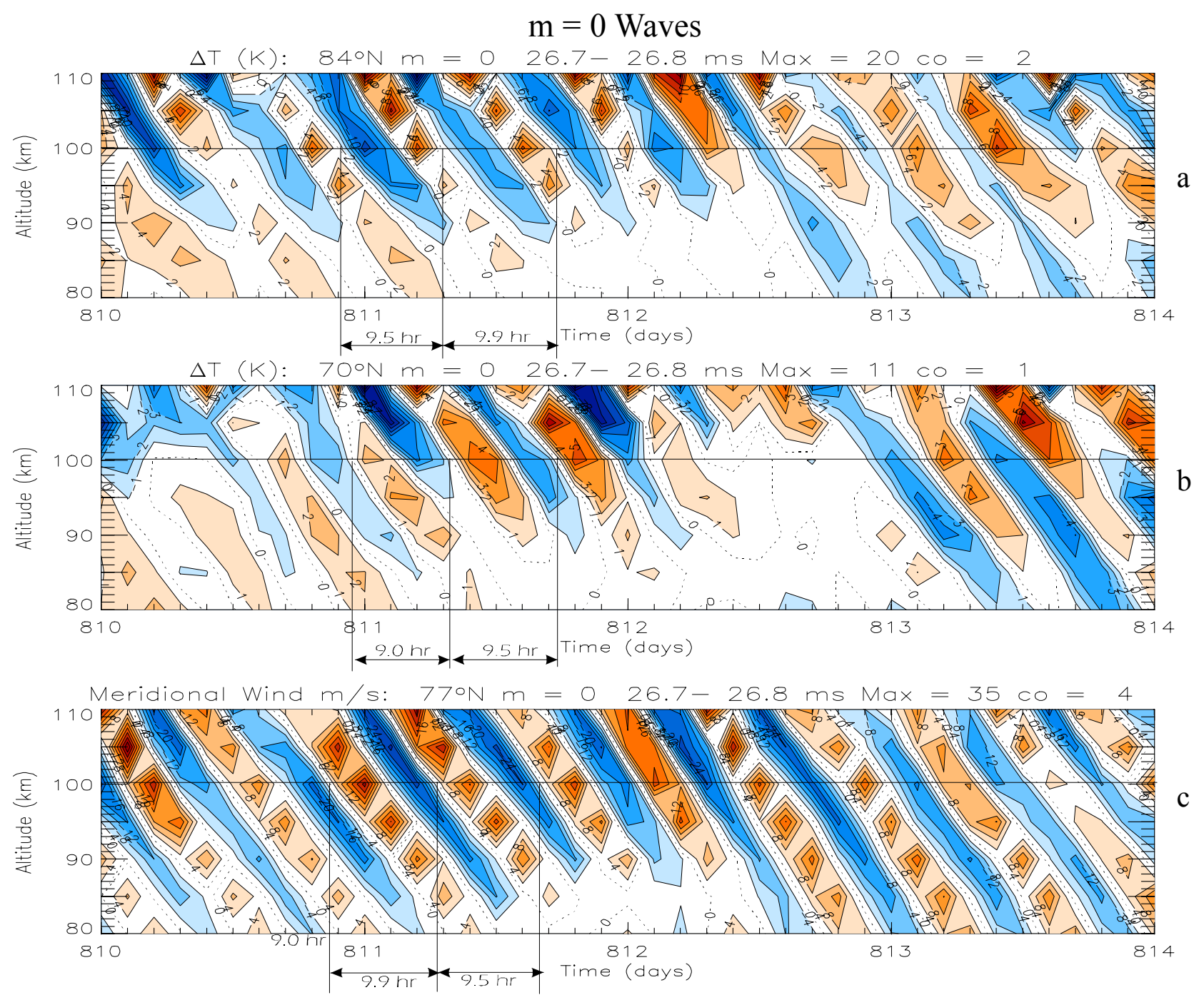

Fig. 2. Similar to Fig. 1 but for $\mathrm{m}=0$ temperature variations at $84^{\circ} \mathrm{N}$ (a) and $70^{\circ} \mathrm{N}$ (b) and related meridional winds at $77^{\circ} \mathrm{N}(\mathbf{c})$. The contour intervals are $2 \mathrm{~K}(\mathrm{a}), 1 \mathrm{~K}(\mathrm{~b})$ and $4 \mathrm{~m} / \mathrm{s}(\mathrm{c})$.

in both the eastward as well as westward propagating waves, clearly indicates that the amplitudes are much larger during the late winter months than in summer.

In many respects, as expected, the wave patterns for the temperature perturbations in Fig. 4 are similar to those in the meridional winds just discussed. The difference is that the largest amplitudes occur in the polar region for $\mathrm{m}=0$, which approach $10 \mathrm{~K}$ at $110 \mathrm{~km}$ in the winter hemisphere. In the other wave numbers, the largest temperature amplitudes are close to $5 \mathrm{~K}$.

The above results describe the maximum amplitudes extracted from a time span of 3 months during the northern winter and spring season. With a running window of 15 days applied in the analysis, the recorded amplitudes represent more than 30 cycles for waves with periods around $10 \mathrm{~h}$. This indicates that the waves are persistent at times with substantial wind and temperature amplitudes.

\subsection{Spectral analysis}

To provide further details about the waves discussed here, we present in Figs. 5 and 6 the amplitude spectra of the meridional winds and temperature perturbations. For the wave numbers a) $m=0, b) m=1$ and c) $m=2$, the spectra are displayed at $100 \mathrm{~km}$ altitude as functions of latitude, covering periods between 8 and $14 \mathrm{~h}$. The spectra for each of the wave numbers displayed contain several wave periods with prominent amplitudes, but the waves are not necessarily excited simultaneously.

The meridional winds for the $\mathrm{m}=0$ waves (Fig. 5a) show a peak with $17 \mathrm{~m} / \mathrm{s}$ near $75^{\circ} \mathrm{N}$, which has a period close to $9 \mathrm{~h}$. Such a wave also appears in the temperature perturbation (Fig. 6a) that peaks in the Arctic with an amplitude of about $5 \mathrm{~K}$, which is consistent with the results presented earlier in Fig. 2. In the Antarctic temperature (Fig. 6a) there is also a stationary semidiurnal 12 -h tide (generated by nonlinear coupling between the migrating tide and planetary waves), 


\section{Meridional Wind}
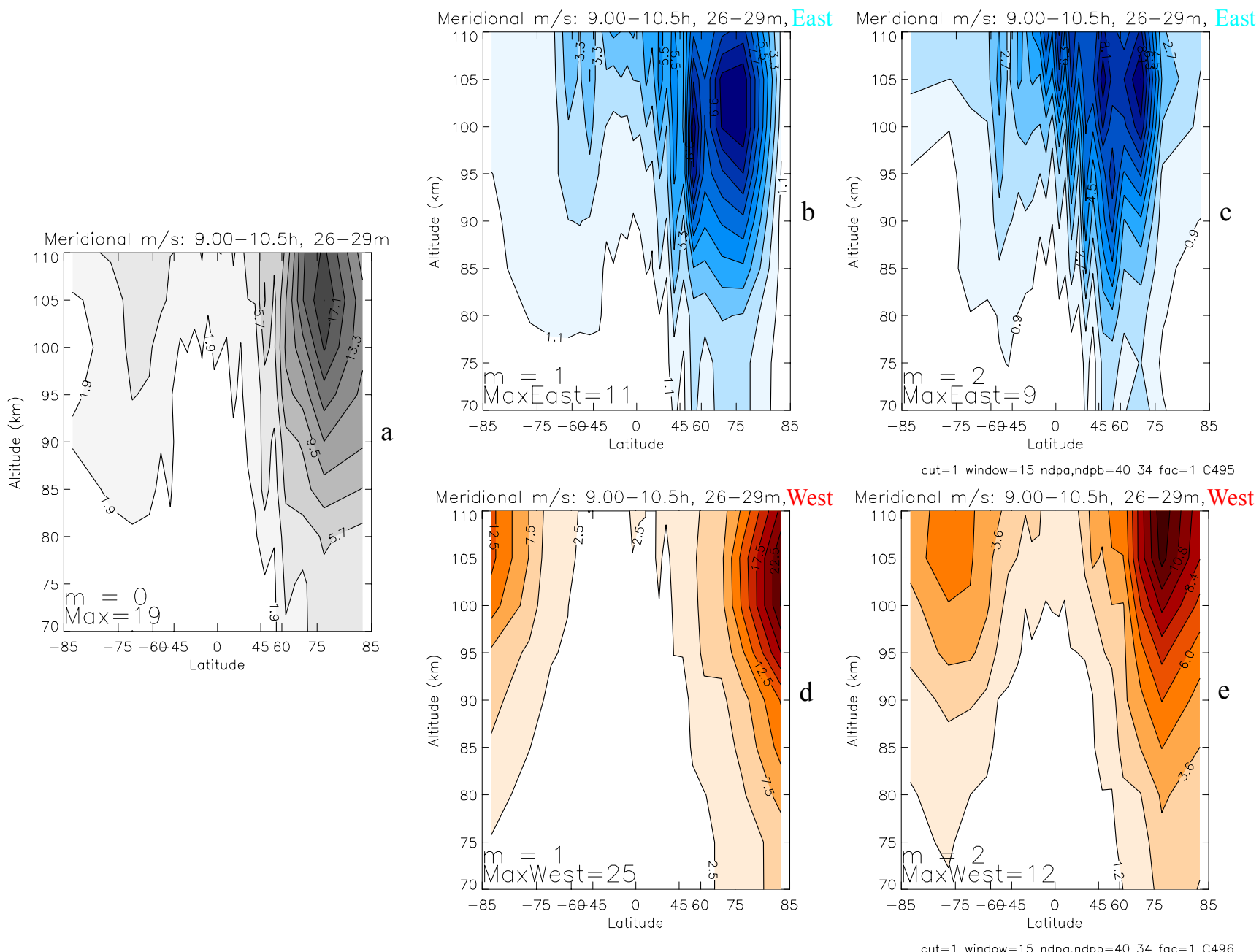

Fig. 3. Maximum meridional wind amplitudes of stationary $m=0$ wave $(\mathbf{a})$, and eastward $(\mathbf{b}$, c) and westward $(\mathbf{d}, \mathbf{e})$ propagating waves $(\mathrm{m}=1$, 2) for periods from 9 to $10.5 \mathrm{~h}$, computed with a running window of 15 days from the time span of 26 to 29 months (March through May of the third model year). Contour plots are presented versus height and latitude, applying the Mercator projection to expand the regions at high latitudes where the waves are prominent. In each panel, the largest amplitudes from the contours are stated.

but apparently it does not produce a meridional wind oscillation that is large enough to appear in the truncated contours of Fig. 5a.

In Fig. 5b, the non-migrating 12-h tide for $\mathrm{m}=1$ dominates in the polar regions, with a maximum amplitude close to $40 \mathrm{~m} / \mathrm{s}$ (at $100 \mathrm{~km}$ ), and it is shown propagating westward. This tide is produced in the NSM with planetary waves, as Forbes et al. (1995) had proposed on the basis of radar measurements. The corresponding westward temperature tide (Fig. 6b) reaches amplitudes close to $5 \mathrm{~K}$ at high latitudes in the Northern Hemsiphere and amplitudes of about $4 \mathrm{~K}$ at equatorial latitudes. For the present paper, the waves of principal interest appear in the amplitude maxima with periods close to 10 and $9 \mathrm{~h}$, which are shown both in the meridional winds (Fig. 5b) and in the temperature perturbations (Fig. 6b). During the 3-month time span, the westward propagating 10-h wave in the Northern Hemsiphere is seen to be weaker than the non-migrating semidiurnal tide, but it still reaches amplitudes close to $24 \mathrm{~m} / \mathrm{s}$ at $84^{\circ}$ latitude and even larger values at the pole. For a more limited time span in March of the third model year, we had shown (Mayr et al., 2003) that the amplitude of the 10-h wave was larger than that of the non-migrating semidiurnal tide, which is not a typical situation but it simulates the scenario Heranandez et al. (1992) encountered. Waves with periods close to 9-h are shown in Figs. $5 \mathrm{~b}$ and $6 \mathrm{~b}$, and they propagate eastward. In contrast to the $m=1$ westward waves that tend to peak at the poles, the much weaker eastward waves do not extend with significant amplitudes into the polar region.

For $\mathrm{m}=2$, Figs. $5 \mathrm{c}$ and $6 \mathrm{c}$ show the large westward migrating 12-h semidiurnal tide that is produced by solar heating, with amplitude maxima close to $50 \mathrm{~m} / \mathrm{s}$ in the winds and more than $15 \mathrm{~K}$ in the temperature variations (variable contour intervals are used to describe these features). In the 


\section{Temperature Perturbation}

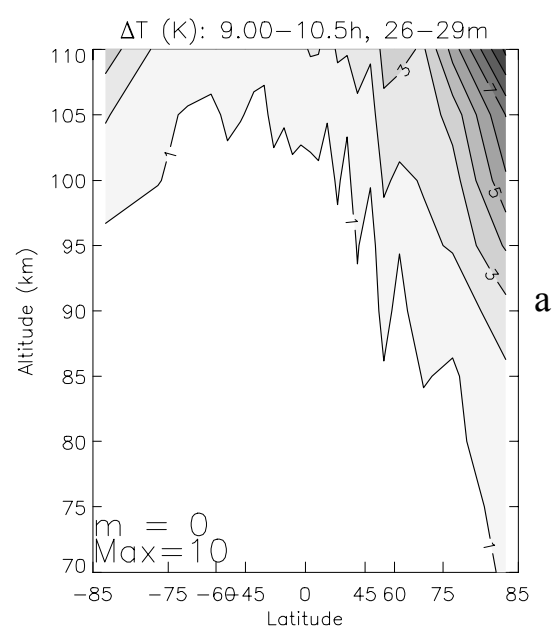

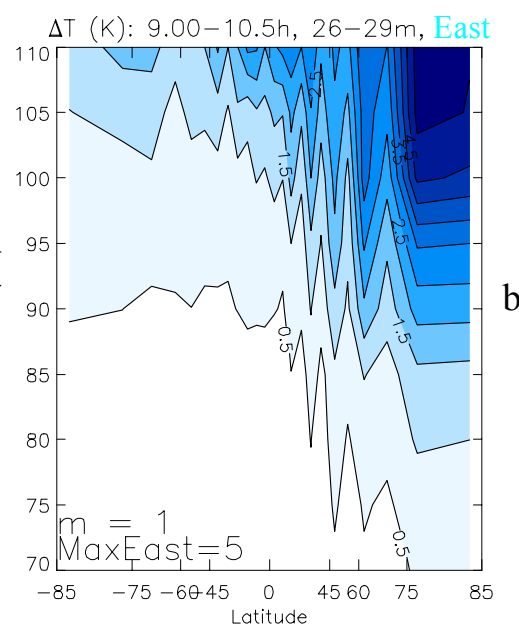
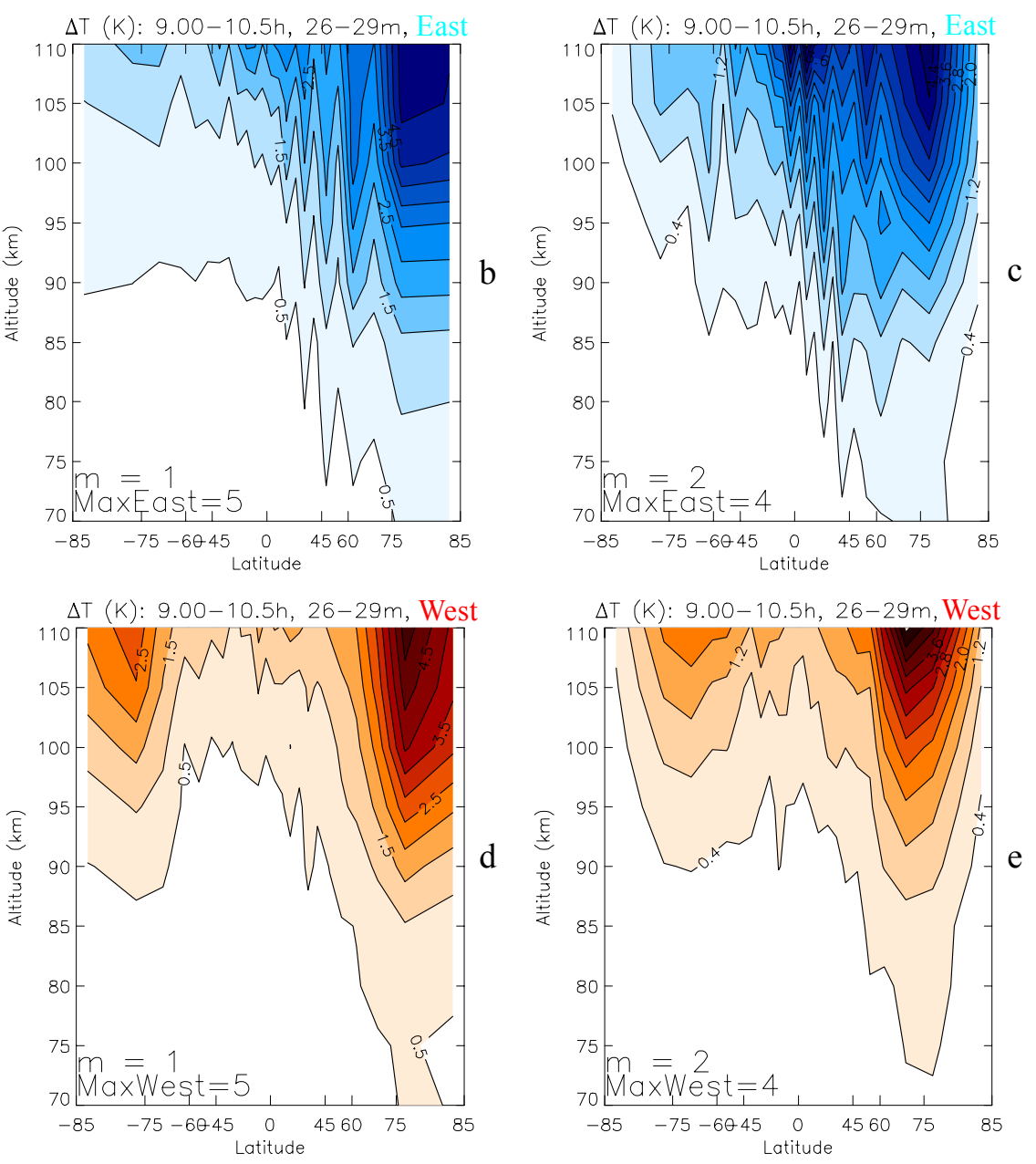

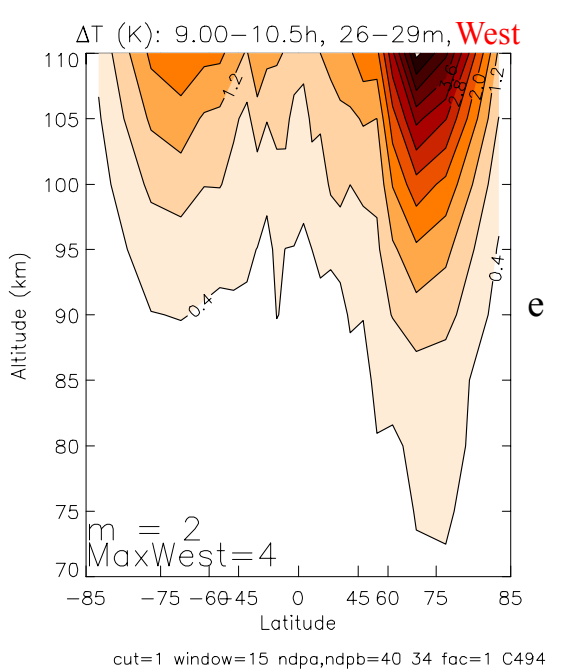

Fig. 4. Similar to Fig. 3 but for temperature perturbations.

Northern Hemsiphere, a westward propagating wave with periods around $10 \mathrm{~h}$ has wind amplitudes close to $10 \mathrm{~m} / \mathrm{s}$ (Fig. 5c), and the corresponding temperature amplitude is only about $2 \mathrm{~K}$ (Fig. 6c). Compared to the westward propagating waves, the eastward waves occupy lower latitudes for $m=2$, as is the case for $m=1$. The eastward waves for the meridional winds, at low to mid latitudes, have amplitudes approaching $10 \mathrm{~m} / \mathrm{s}$ with periods close to 9 and $11 \mathrm{~h}$ and the related temperature amplitudes are about $3 \mathrm{~K}$.

To reveal the nature of the waves discussed here, we present with Fig. 7 contour plots of snapshots for the eastward and westward propagating components. We chose a time span in mid September of the third model year when pronounced waves with 9-h periodicity are generated in the Southern Hemisphere. An analysis was then performed to extract the average wave characteristics, i.e. phase and amplitude as functions of altitude and latitude, delineating the eastward and westward components. The patterns described in Fig. 7 are considered representative of the waves discussed. With a horizontal wavelength of about $40^{\circ}$ in latitude, the latitudinal variations of the eastward and westward propagating waves differ significantly, as seen already from Figs. 3 through 6 . The vertical wavelength of about $25 \mathrm{~km}$ is similar to that shown in Figs. 1 and 2. The relationship between meridional and vertical wavelengths, revealed in the wave patterns shown, supports our interpretation (Mayr et al., 2003) that we are dealing with internal planetary scale inertio gravity waves (IGW) related to the Class I waves discussed in the classical literature (Longuett-Higgins, 1968).

\subsection{Seasonal variations}

The IGWs presented here exhibit pronounced seasonal variations as shown in Figs. 8 and 9, respectively, for the meridional winds and temperature variations at $100 \mathrm{~km}$ altitude. The amplitudes for a) $m=0$ and those for $m=1$ propagating b) eastward and c) westward are plotted versus latitude and time covering 24 months. In both hemispheres, these wave components tend to be excited preferentially during winter months, beginning in late fall and extending into spring. 

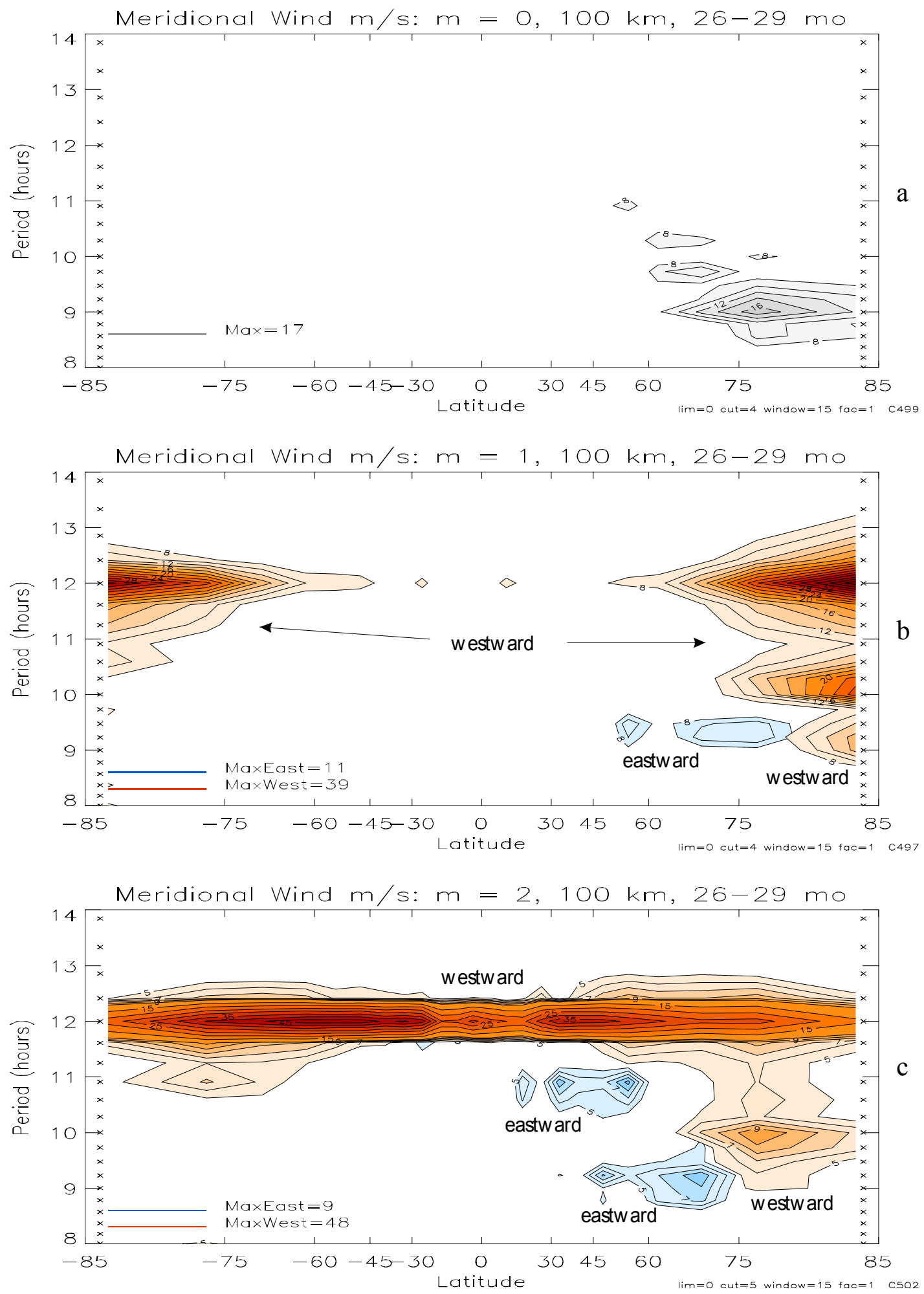

Fig. 5. Maximum amplitude spectra for zonal wave numbers $m=0(\mathbf{a}), \mathrm{m}=1$ (b) and $\mathrm{m}=2$ (c) at $100 \mathrm{~km}$ for periods between 8 and $14 \mathrm{~h}$, computed from the 26 to 29 months time span (March through May) with a running window of 15 days. The gray scale is used for m=0 (no propagation), red for westward, and blue for eastward propagation. In (b) and (c), the contour intervals are variable to describe the large migrating and non-migrating tides. To eliminate clutter, the lowest $40 \%$ or $50 \%$ of contours are suppressed. The largest amplitudes from the contours are stated in each panel. The x-marks on the vertical axes denote the discrete periods for which the maximum amplitudes are computed to produce the contours. 

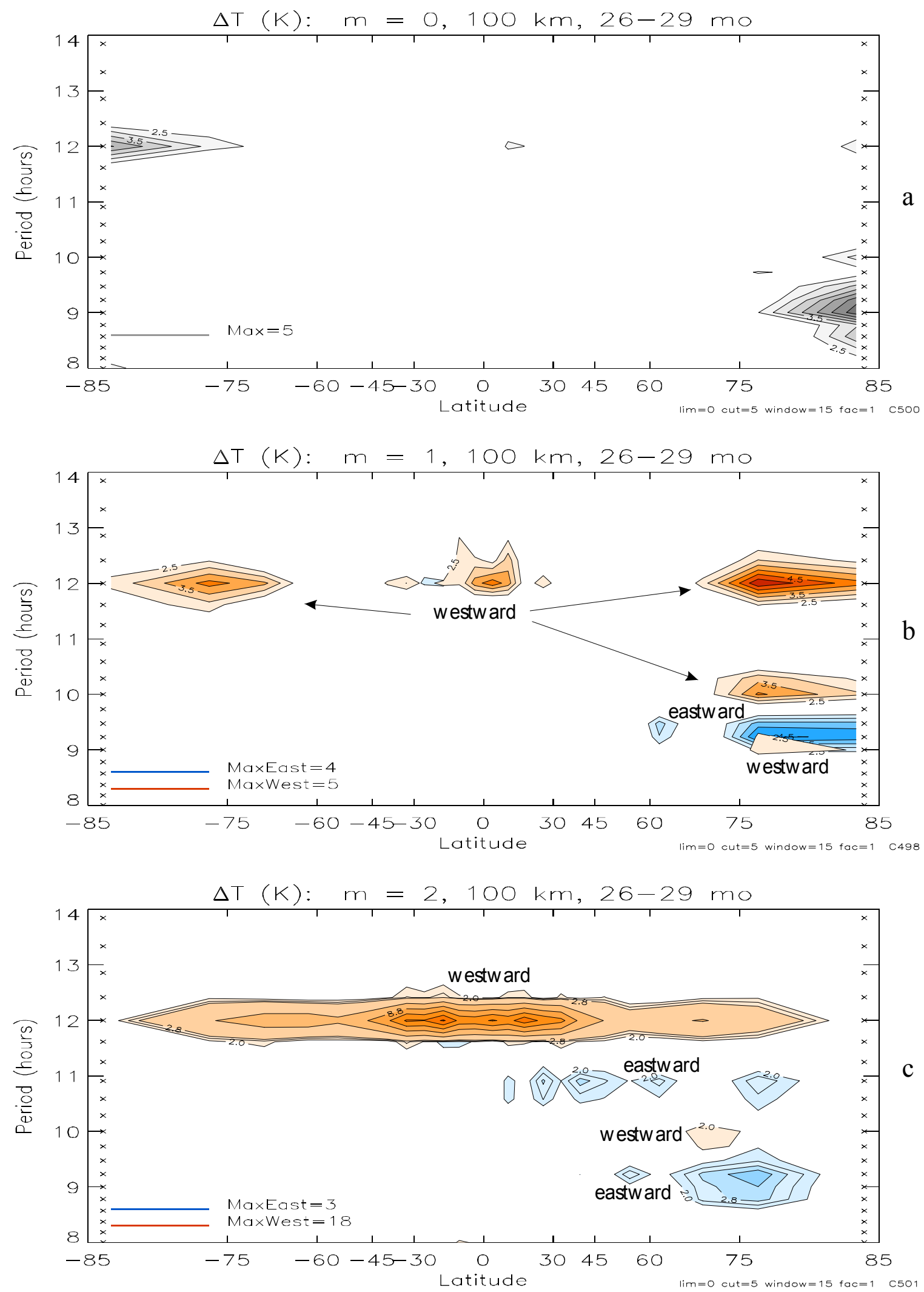

Fig. 6. Similar to Fig. 5 but for temperature perturbations. 

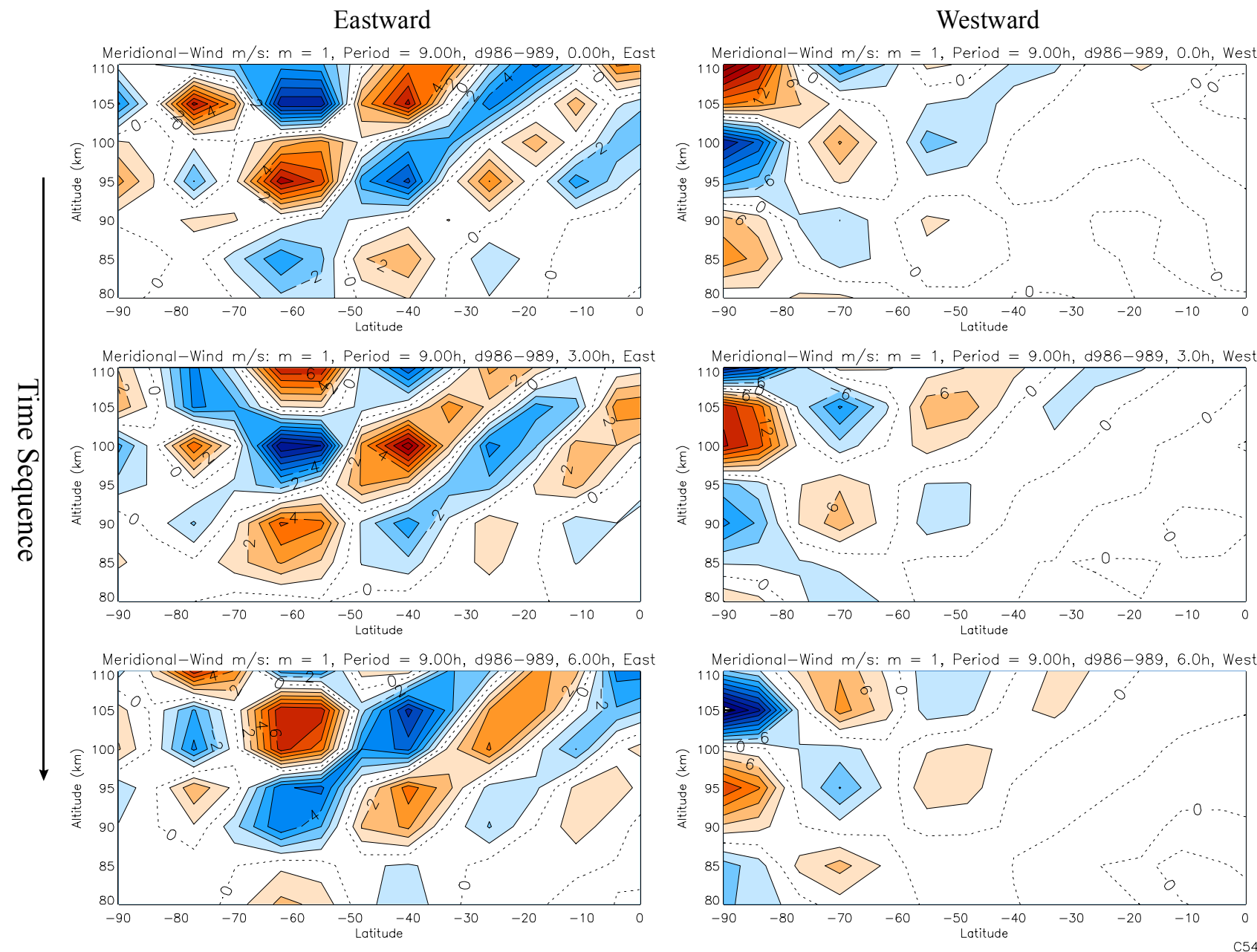

Fig. 7. Snapshots of the meridional winds in the Southern Hemisphere near 32.5 months (mid September), when waves are most prominent. The winds are derived from 3-day time spans to describe the 9-h westward and eastward propagating waves. Plotted with 3-h time intervals, the phase of the waves is shown progressing downwards. (Since the numerical results are recorded with 5-km increments, the contours appear ragged.)

Consistent with the results shown earlier, the westward propagating waves for the meridional winds with wave number $\mathrm{m}=1$ (Fig. 8c) are largely confined to high latitudes. The eastward propagating waves (Fig. 8b), in contrast, do not extend with significant amplitudes into the polar regions but instead extend to low latitudes and across the equator. These patterns are characteristic of the seasonal and latitudinal variations throughout the mesosphere above $50 \mathrm{~km}$.

In the temperature variations (Fig. 9), the waves with $m=0$ a) are largest at polar latitudes. Consistent with the waves in the meridional winds for $\mathrm{m}=1$, the corresponding temperature amplitudes for the westward component are also largest at high latitudes (Fig. 9c), but they vanish at the poles. And the eastward waves (Fig. 9b) extend with substantial amplitudes (almost $5 \mathrm{~K}$ ) towards equatorial latitudes. The wave patterns for $\mathrm{m}=2,3$ and 4 (not presented) reveal similar trends in the seasonal variations: i.e. the amplitudes tend to be largest during winter months approaching spring.
We carried out numerical experiments to shed some light on the possible excitation mechanisms for the waves. When the energy sources for the solar migrating diurnal and semidiurnal tides are turned off, the IGWs are still excited, as shown in Fig. 10 for the meridional winds with $m=1$. Compared to Figs. 8b,c the amplitudes in Fig. 10 are of comparable magnitude (about $24 \mathrm{~m} / \mathrm{s}$ maximum westward and $11 \mathrm{~m} / \mathrm{s}$ eastward). However, without the tidal excitation, the seasonal variations are significantly different. In Fig. 10, the largest amplitudes tend to occur around equinox during the fall and spring seasons, in contrast to the wave patterns seen in Fig. 8 that show the waves to be predominant during the winter and spring seasons. This indicates that the tides come into play in generating the IGWs, and it is reasonable to suggest that nonlinear coupling between semidiurnal tide and $m=3$ planetary waves with periods close to 2 days is the likely excitation mechanism, as had been suggested in the literature (e.g. Manson et al., 1982; Manson and Meek, 1990; Ruster, 1994; Sivjee et al., 1994; Portnyagin et al., 2000; Wu et al., 2002). 

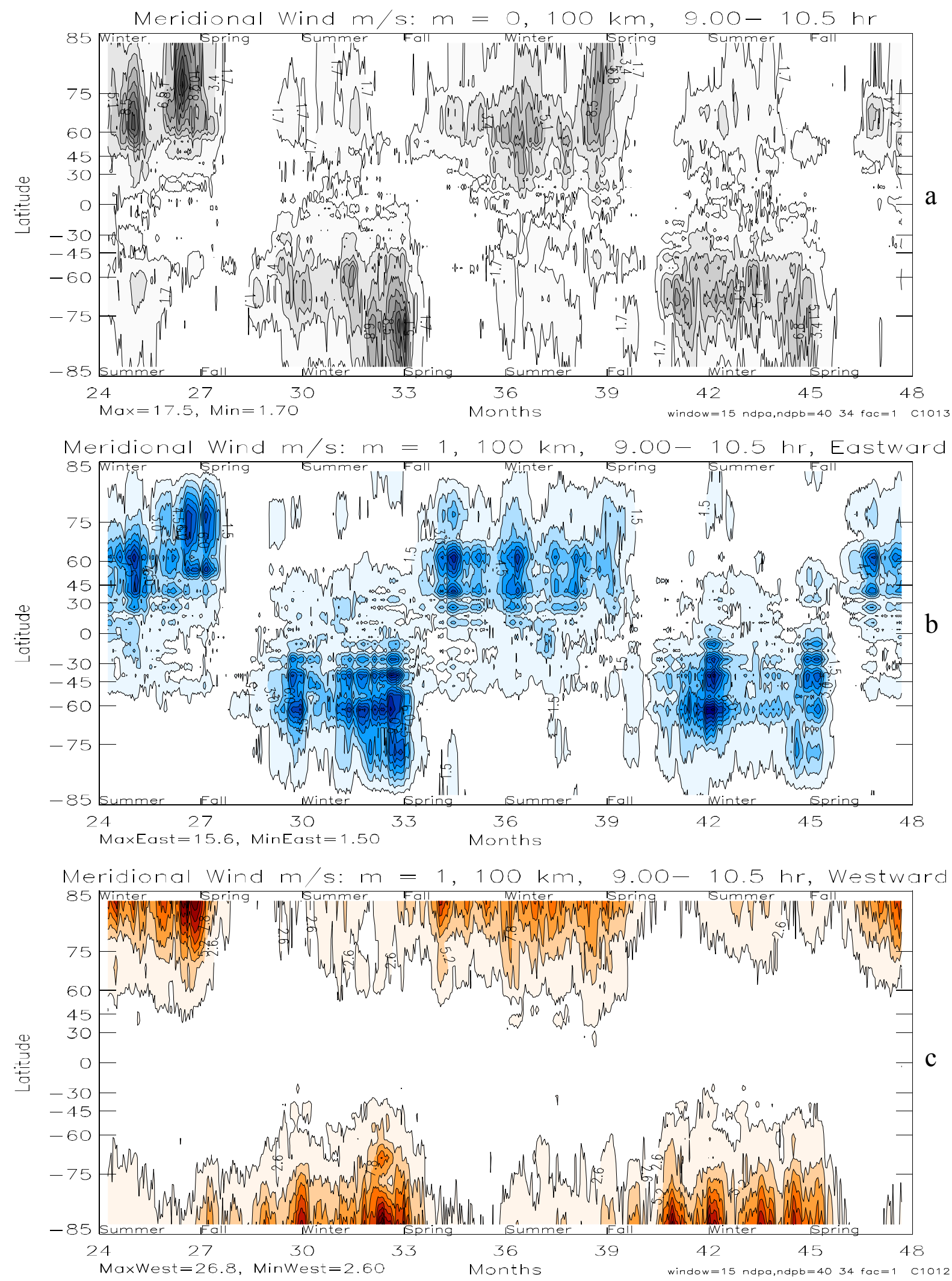

Fig. 8. To characterize the seasonal and latitudinal variations in the meridional winds at $100 \mathrm{~km}$, wave amplitudes are presented for the stationary waves with $\mathrm{m}=0(\mathbf{a})$, and the eastward (b) and westward (c) propagating $\mathrm{m}=1$ components. For periods between 9 and $10.5 \mathrm{~h}$, a moving window of 15 days is applied. Maximum (and minimum) amplitudes (m/s) are stated, i.e. 17.5 (a), 15.6 (b) and 26.8 (c). 

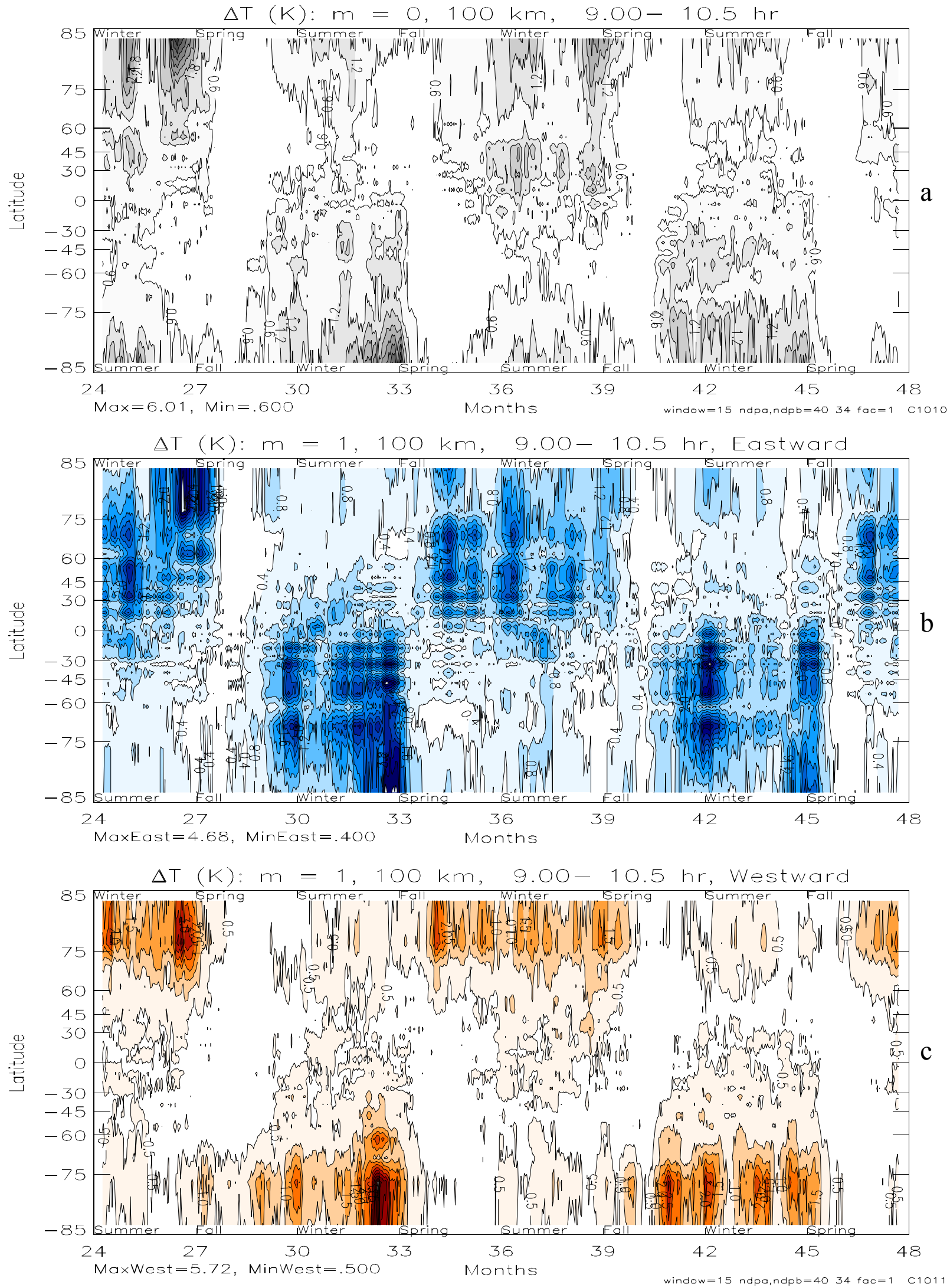

Fig. 9. Like Fig. 8 but for temperature variations with maximum amplitudes (K): 6 (a), 4.7 (b), 5.7 (c). 

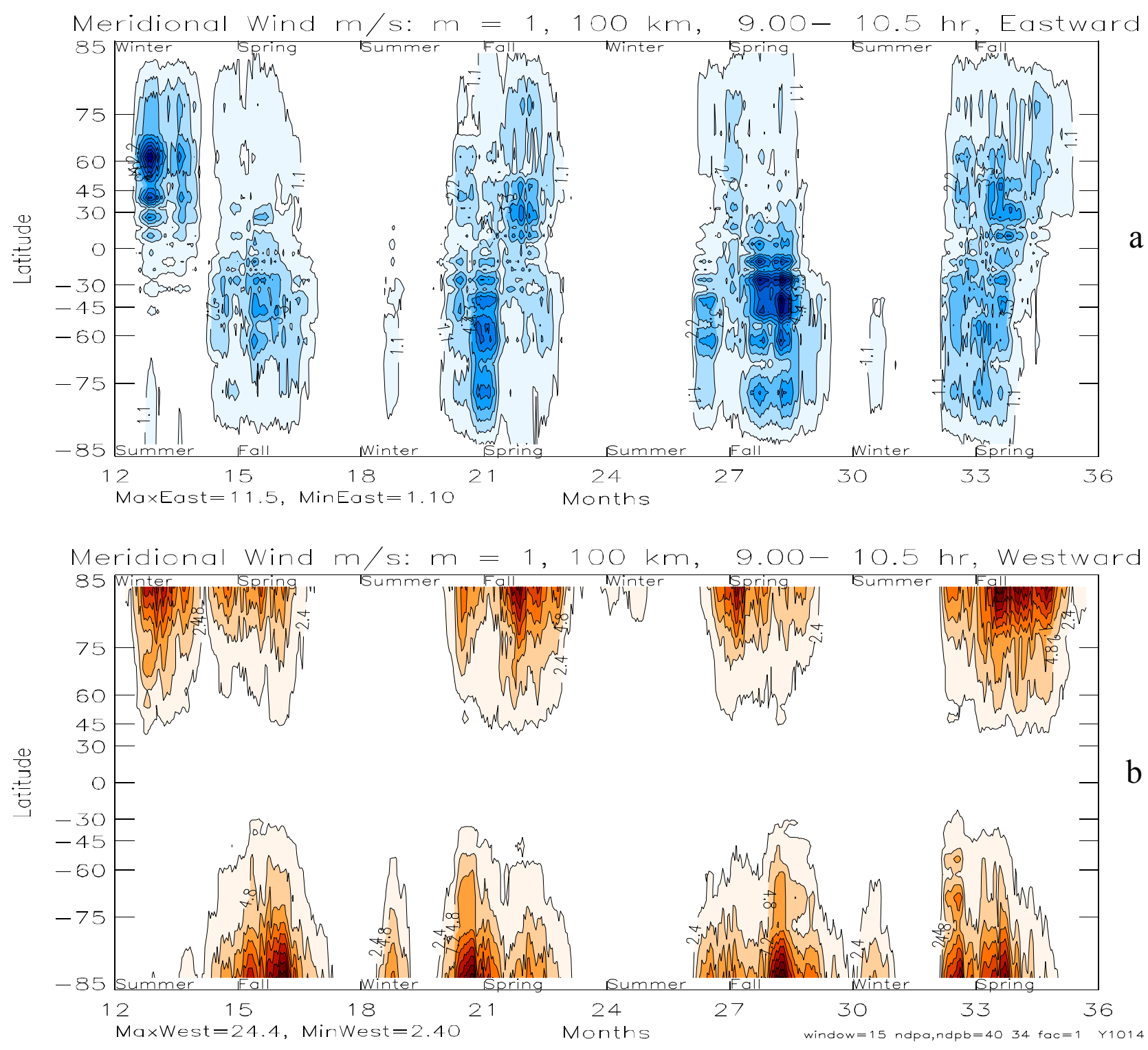

Fig. 10. Similar to Fig. 8 but computed without excitation of the migrating diurnal and semidiurnal tides.

The relationship between IGWs and planetary waves (PW) is also indicated from the resemblance of their seasonal variations. This is demonstrated with Fig. 11, where we show for comparison the PWs that appear in the model at $60 \mathrm{~km}$. For PWs with $m=1$ and 3 (as well as $m=2$ and 4 , not shown), the seasonal variations in the meridional winds closely resemble those seen in the IGWs (Fig. 8). In both hemispheres, at this altitude, the PWs (and IGWs, not shown) are more prevalent during the winter and spring seasons. The similarity in the seasonal variations, however, does not extend into the upper mesosphere, where the PWs tend to be larger in summer (Mayr et al., 2004) unlike the IGWs. With their longer oscillation periods, the slower propagating PWs interact with the zonal winds that reverse direction above $70 \mathrm{~km}$. The much faster IGWs, in contrast, propagate through the mesosphere virtually unperturbed, except for viscous dissi- pation. As these waves propagate to higher altitudes and increase in amplitude, the pattern in their seasonal variations thus essentially remains unchanged.

Numerical experiments show that the IGWs and PWs essentially disappear when the solar heating is turned off which drives the zonal mean $(\mathrm{m}=0)$ circulation and related temperature and pressure variations. Directly or indirectly through the PWs, the IGWs are likely produced by the instabilities that arise in the zonal mean circulation. Plumb (1983) proposed the baroclinic instability for generating the 2-day PWs, and Chan et al. (1994b) suggested that it produced the 4-day wave in their model. In discussing the PWs that are generated in our model (Mayr et al., 2004), the differences between the relative density and pressure variations for $m=0$ were evaluated to produce a measure of baroclinicity. It showed that the relative gradients are largest in winter at 50 and $70 \mathrm{~km}$, but 

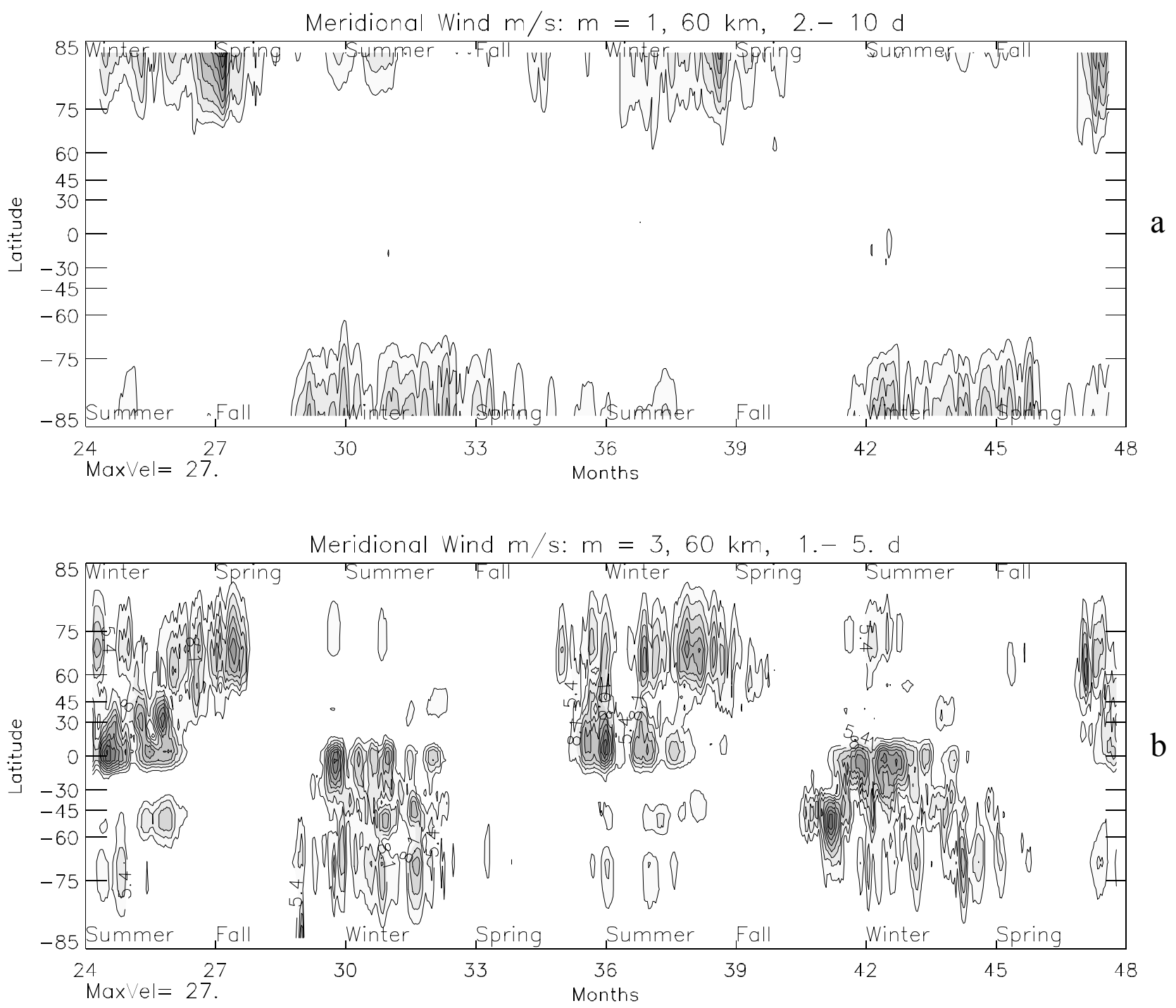

Fig. 11. Computed seasonal variations of meridional winds at $60 \mathrm{~km}$ for planetary waves with zonal wave numbers $\mathrm{m}=1$ and 3 . The resemblance with the seasonal variations of the IGWs in Fig. 8 indicates that both classes of waves have similar roots as discussed in the main text.

are larger in summer at $90 \mathrm{~km}$. This pattern in the seasonal variations related to baroclinicity, including the variations with altitude, resembles the behavior seen in the PWs, which suggests that the baroclinic instability is indeed involved in exciting the waves. For the faster propagating IGWs, the seasonal variations would be dictated by the instability conditions below $70 \mathrm{~km}$.

\section{Discussions and conclusions}

As we had pointed out earlier (Mayr et al., 2003), waves of the kind described here have been discussed in the classical literature by Longuett-Higgins (1968), who classified them as Class I waves. These waves have also been referred to as Inertio Gravity Waves (Volland, 1988; Andrews, Holton, and Leovy, 1987), which is appropriate since the Coriolis force is still important for periods close to $12 \mathrm{~h}$. Except for the excitation mechanism, the waves have the properties of atmospheric diurnal tides. Due to the action of the Coriolis force, the eastward and westward propagating components differ significantly. For the $m=1$ waves in Longuett-Higgins (1968) specifically, the westward wave thus peaks at the poles while the eastward wave tends to peak at mid latitudes - which is consistent with the numerical results earlier presented. Since the waves discussed here have zonal wave numbers $m=0$ to 4 , we refer to them as planetary-scale inertio gravity waves (IGW). This distinction is justified in light of the inertio gravity waves observed in the middle atmosphere that have much shorter horizontal wavelengths (e.g. Fritts, 1984).

As seen from the numerical results presented, and in particular from Figs. 8 and 9, the IGWs reveal persistent seasonal variations. Throughout the years, the IGWs tend to be 
strongest in winter and spring, and they are decidedly weaker during summer months. Although not shown, this pattern in the seasonal variations of the IGWs is prevalent throughout the mesosphere. Such a pattern is also seen in the planetary waves (PWs) at altitudes around $60 \mathrm{~km}$ (Fig. 11), and the apparent similarity suggests that both classes of waves have similar roots.

We have shown with Fig. 10 that the IGWs still appear in the model when the migrating tides are not excited. The periods and amplitudes then are similar, which demonstrates that the tides are not essential to generate the IGWs, in principal. The waves under this condition, however, are different, especially their seasonal variations - and this indicates that the tides also do come into play. As pointed out earlier, nonlinear coupling between the semidiurnal tide and 2-day planetary waves for $m=3$ has been proposed in the literature as a mechanism to excite IGWs with periods of about 10 and $16 \mathrm{~h}$. A prominent candidate for such interaction is the filtering of small-scale gravity waves $(\mathrm{GW})$, parameterized in the NSM, which has been shown to produce nonlinear coupling between PWs and migrating tides to generate non-migrating tides. In light of the differences obtained with tidal excitation (Fig. 8) and without (Fig. 10), we are therefore amending our earlier interpretation (Mayr et al., 2003) by concluding that tide-PW interactions must additionally be involved to fully explain the seasonal variations of the IGWs.

When we turn off the solar heating that drives the $m=0$ temperature, pressure and wind fields, the IGW disappear, like the PWs. (Presently, there is no explicit source in the model to generate PWs or IGWs due to tropospheric convection or flow over topography, for example.) The IGWs are completely generated internally by the instabilities that can develop in the zonal mean circulation, and the baroclinic instability is a prominent candidate. Our results suggest that instabilities excite the IGWs directly and also indirectly through the PWs that interact with tides.

Although the IGWs and PWs appear to have similar roots in the way they are produced, their propagation characteristics in the mesosphere are significantly different. With their low oscillation periods and large planetary-scale wavelengths, the fast IGWs can propagate through the atmosphere without encountering critical levels. Except for viscous dissipation, the waves thus propagate virtually without attenuation to reach thermospheric altitudes. In contrast, the slower PWs can interact with the zonal circulation. The result is that the oscillation periods of the PWs are modified, and the character of the waves undergoes drastic changes, affecting the propagation direction and seasonal variations. This is apparent, for example, in the modeled PWs shown in Fig. 11 that prevail at $60 \mathrm{~km}$ in the winter hemisphere, but are more prevalent at $90 \mathrm{~km}$ in the summer hemisphere (not shown).

The fast planetary-scale IGWs discussed also differ from the inertio gravity waves with much lower phase speeds earlier mentioned, which make up the long period component of the saturated gravity wave spectrum in the middle atmosphere (Fritts, 1984). Such inertio gravity waves have been observed with radars (e.g. Fritts et al., 1984; Muraoka et al.,
1988, 1994; Tsuda et al., 1989), and they have horizontal wavelengths between 500 and $3000 \mathrm{~km}$ and periods between 5 and $11 \mathrm{~h}$. These waves propagate with phase speeds that are close to the background zonal wind velocities, so that they are subject to critical level absorption and dissipation, which is evident from the observed altitude invariance of their amplitudes.

Without tidal excitation and in certain seasons, the NSM produces IGWs with a spectrum that contributes significantly to the 12-h periodicity, so that semidiurnal tides are effectively generated. These pseudo-tides will be discussed in a separate paper. ${ }^{1}$

Acknowledgements. The authors are indebted to two anonymous referees for valuable comments, which greatly contributed to improve the paper.

Topical Editor U.-P. Hoppe thanks two referees for their help in evaluating this paper.

\section{References}

Akmaev, R. A.: Simulation of large-scale dynamics in the mesosphere and lower thermosphere with the Doppler-spread parameterization of gravity waves: 1 . Implementation and zonal mean climatologies, J. Geophys. Res., 106, 1193-1204, 2001.

Andrews, D. G., Holton, J. R., and Leovy, C. B.: Middle Atmosphere Dynamics, Academic Press, Orlando, 1987.

Chan, K. L., Mayr, H. G., Mengel, J. G., and Harris, I.: A "stratified" spectral model for stable and convective atmospheres, J. Comp. Phys., 113, 165-176, 1994a.

Chan, K. L., Mayr, H. G., Mengel, J. G., and Harris, I.: A spectral approach for studying middle and upper atmospheric phenomena, J. Atm. Terr. Phys., 56, 1399-1419, 1994b.

Forbes, J. M. and Garrett, H. B.: Thermal excitation of atmospheric tides due to insolation absorption by $\mathrm{O}_{3}$ and $\mathrm{H}_{2} \mathrm{O}$, Geophys. Res. Lett., 5, 1013-1016, 1978.

Forbes, J. M., Makarov, N. A., and Portnyagin, Y. I.: First results from the meteor radar at South Pole: A large 12-h oscillation with zonal wave number one, Geophys. Res. Lett., 22, 32473250, 1995.

Forbes, J. M., Palo, S. E., Zhang, X., Portnyagin, Y. I., Makarov, N. A., and Merzlyakov, E. G.: Lamb waves in the lower thermosphere: Observational evidence and global consequences, J. Geophys. Res., 104, 17 107-17 115, 1999.

Fraser, G. J.: Summer circulation in the Antarctic middle atmosphere, J. Atm. Terr. Phys., 46, 143-146, 1984.

Fritts, D. C.: Gravity wave saturation in the middle atmosphere: A review of theory and observations, Rev. Geophys. Space Phys., 22, 275-308, 1984.

Fritts, D. C., Balsley, B. B., and Ecklund, W. L.: VHF echoes from the arctic mesosphere and lower thermosphere, Part II: Interpretations, in Dynamics of the Middle Atmosphere, Eds., J. R. Holton and T. Matsuno, 97-115, 1984.

Hernandez, G., Smith, R. W., Fraser, G. J., and Jones, W. L.: Largescale waves in the upper mesosphere at antarctic high-latitudes, Geophys. Res. Lett., 19, 1347-1350, 1992.

Hernandez, G., Fraser, R. W., and Smith, G. J.: Mesospheric 12-h oscillation near south pole antarctica, Geophys. Res. Lett., 20, 1787-1790, 1993.

\footnotetext{
${ }^{1}$ E. R. Talaat - private communication.
} 
Hines, C. O.: Doppler-spread parameterization of gravity-wave momentum deposition in the middle atmosphere, 1, Basic formulation, J. Atmos. Solar Terr. Phys., 59, 371-386, 1997a.

Hines, C. O.: Doppler-spread parameterization of gravity-wave momentum deposition in the middle atmosphere, 2, Broad and quasi monochromatic spectra, and implementation, J. Atmos. Solar Terr. Phys., 59, 387-400, $1997 \mathrm{~b}$.

Longuett-Higgins, M. S.: The eigenfunctions of Laplace's tidal equations over a sphere, Phi. Trans. Roy. Soc. London, A262, 511-607, 1968.

Manson, A. H., Meek, C. E., Gregory, J. B., and Chakrabarty, D. K.: Fluctuations in the tidal $(24,12 \mathrm{~h})$ characteristics and oscillations (8h-5d) in the mesosphere and lower thermosphere (70-110 km): Saskatoon $\left(52^{\circ} \mathrm{N}, 107^{\circ} \mathrm{W}\right)$, Planet. Space Sci., 30, 1283-1294, 1982.

Manson, A. H. and Meek, C. E.: Long period (8-20 h) wind oscillations in the middle atmosphere at Saskatoon $\left(52^{\circ} \mathrm{N}\right)$ : Evidence for nonlinear tidal effects, Planet. Space Sci., 38, 1431-1441, 1990.

Manzini, E., McFarlane, N. A., and McLandress, C.: Impact of the Doppler spread parameterization the simulation of the middle atmosphere circulation using the MA/ECHAM4 general circulation model, J. Geophys. Res., 102, 25 751-25 762, 1997.

Mayr, H. G., Mengel, J. G., Chan, K. L., and Porter, H. S.: Mesosphere dynamics with gravity forcing: Part II, Planetary waves, J. Atm. Solar-Terr. Phys., 63, 1865-1881, 2001.

Mayr, H. G., Mengel, J. G., Talaat, E. R., Porter, H. S., and Chan, K. L.: Planetary-scale inertio gravity waves in the mesosphere, Geophys. Res. Lett., 30 (23), Art.-No. 2228, 2003.

Mayr, H. G., Mengel, J. G., Talaat, E. R., Porter, H. S., and Chan, K. L.: Modeling study of mesospheric planetary waves: Genesis and characteristics, Ann. Geophys., 22 (6), 1885-1902, 2004.

Mengel, J. G., Mayr, H. G., Chan, K. L., Hines, C. O., Reddy, C. A., Arnold, N. F., Porter, H. S.: Equatorial oscillations in the middle atmosphere generated by small-scale gravity waves, Geophys. Res. Lett., 22 , 3027-3030, 1995.
Muraoka, Y, Sugyama, T., and Kawahira, K.: Cause of a monochromatic inertio-gravity wave breaking observed by the MU radar, Geophys. Res. Lett., 15 , 1349-1352, 1988.

Muraoka, Y, Fukao, S., Sugyama, T., Yamamoto, M., Nakamuro, T., Tsuda, T., and Kato, S.: Features of a mesospheric inertiogravity wave observed with the MU radar, J. Atm. Terr. Phys., 56, 1163-1171, 1994.

Plumb, R. A.: Baroclinic instability of the summer mesosphere: A mechanism for the quasi-2-day wave?, J. Atmos. Sci., 40, 262270, 1983.

Portnyagin Y. I., Forbes, J. M., Merzlyakov, E. G., Makarov N. A., and Palo, S. E: Intra-diurnal wind variations observed in the lower thermosphere over the South Pole, Ann. Geophys., 18, 547-554, 2000.

Ruster, R.: VHF radar observations of nonlinear interactions in the summer polar mesosphere, J. Atm. Terr. Phys., 56, 1289-1299, 1994.

Sivjee, G. G., Walterscheid, R. L., and McEwen, D. J.: Planetary wave disturbances in the Arctic winter mesopause over Eureka $\left(80^{\circ} \mathrm{N}\right)$, Planet. Space Sci., 42, 973-986, 1994.

Strobel, D. F.: Parameterization of atmospheric heating from 15 to $120 \mathrm{~km}$ due to $\mathrm{O} 2$ and $\mathrm{O} 3$ absorption of solar radiation, J. Geophys. Res., 83, 6225-6230, 1978.

Tsuda, T., Inoue, T., Fritts, D. C., VanZandt, T. E., Kato, S., Sato, T., and Fukao, S.: MST radar observations of a saturated gravity wave spectrum, J. Atm. Sci., 46, 2440-2447, 1989.

Volland, H.: Atmospheric Tidal and Planetary Waves, Kluwer Academic Publ., Boston, MA, 1988.

Wu, Q., Killeen, T. T., McEwen, D., Solomon, S. C., Guo, W., Sivjee, G. G., and Reeves, J. M.: Observation of the mesospheric and lower thermospheric $10-\mathrm{h}$ wave in the northern polar region, J. Geophys. Res., 107, Art. No. 1082, 2002.

Zhu, X: Radiative cooling calculated by random band models with S-1-beta tailed distribution, J. Atmos. Sci., 46, 511-520, 1989. 